\title{
A stiff collar can restrict atlantoaxial instability in rheumatoid cervical spine in selected cases
}

\author{
M Kauppi, P Anttila
}

\begin{abstract}
Objective-To study the efficiency of a stiff collar in restricting the instability of anterior atlantoaxial subluxation (AAS). Methods-Twenty two successive patients with an unstable AAS were studied. Lateral view radiographs were taken of the cervical spine in flexion, extension, and neutral positions without a collar, and in full flexion with a custom made stiff collar.

Results-The collar restricted more than $30 \%$ of the maximal instability of the AAS in $50 \%$ of the patients. These patients had significantly shorter atlantoaxial distance in the neutral position than those in whom the collar was not able to restrict the instability.

Conclusion-A stiff collar can restrict the atlantoaxial instability in selected rheumatic patients with an unstable AAS. Lateral view radiographs of the cervical spine in a neutral position can be used to identify the patients whom the collar will benefit.
\end{abstract}

(Ann Rheum Dis 1995; 54: 305-307)

Involvement of the cervical spine is a characteristic and potentially fatal aspect of the clinical picture of rheumatoid arthritis (RA). Several types of rheumatoid changes occur in the cervical spine, anterior atlantoaxial subluxation (AAS) being the most common. ${ }^{1-5}$ AAS is diagnosed by lateral view radiographs taken during flexion. The displacement may be reducible in extension, but irreducible deformities are not rare. ${ }^{5-7}$ The AAS may be asymptomatic, but the patient may have pain, and sometimes neurological symptoms.

The prevalence of AAS has been reported to vary from 19 to $70 \%$ in RA patients. ${ }^{58}$ Only selected cases proceed to surgery; ${ }^{1-5}$ most patients are treated conservatively, typically with cervical collars. It is a common opinion that collars offer psychological support, and warmth to the tensile muscles, but do not restrict the critical abnormal atlantoaxial instability. ${ }^{4}{ }^{7}$ This view is based mainly on the widely cited results of Althoff and Goldie, ${ }^{7}$ who tested four types of cervical orthoses and concluded that none restricted the pathological extent of rheumatoid AAS. The harder collars seemed to force the atlas to subluxate anteriorly in some of the patients. However, patient selection for that study may be criticised as flawed. The question of the possibility of stabilising AAS by means of a collar is very important for many rheumatoid patients, creating a need for more research.

\section{Patients and methods}

We studied 22 successive rheumatoid patients with unstable AAS presenting to the Rheumatism Foundation Hospital, Heinola, Finland. The table summarises their demographic data. Each one had AAS of at least $5 \mathrm{~mm}$ in flexion, which was at least $4 \mathrm{~mm}$ smaller during extension.

A custom made 'stiff' collar (figure) was prepared for each patient, made of closed cell polyethylene foam sheeting $1.25 \mathrm{~cm}$ thick (Plastazote ${ }^{\circledR}$ ). The collars were constructed to prevent flexion, and the anterior part strengthened by plastic chips; the posterior part was more flexible, and not very high. They were side opening and fastened by a strap. This type of collar is routinely used in our hospital, when a 'stiff collar' is needed.

Lateral view radiographs of the cervical spine were taken in full flexion, in extension, and in a neutral position without the collar, and in full flexion with the collar in place.

The distance between the posterior aspect of the anterior arch of the atlas and the anterior aspect of the axis was measured in all the radiographs; it is referred to in this text as the atlantoaxial (AA) distance. The difference in AA distance between the flexion and extension radiographs was measured and termed the 'instability'. The difference between instability values with the collar and without the collar reflected the efficiency of the collar in preventing the anterior subluxation of the atlas. The radiographs were studied by both authors. For two patients, neutral position radiographs were not available.

\section{Results}

Without the collar, the AA distance was from 5 to $10 \mathrm{~mm}$ during flexion; during extension it was $0-3 \mathrm{~mm}$ (table). The first two flexion radiographs taken with the collar in place showed that the collar restricted the AA distance, but in the third case, the AA distance was unchanged. We thought that some difference may exist between patients in whom AAS is restricted and in whom it is not, therefore we decided to take additional radiographs with no collar and the cervical spine in a neutral position. The first two 
Demographic details of 21 patients with rheumatoid arthritis $(R A)$ and one patient (No 10) with $R A$ type mixed connective tissue disease, listed in descending order of effectiveness of the collar

\begin{tabular}{|c|c|c|c|c|c|c|c|c|c|c|}
\hline \multirow{3}{*}{$\begin{array}{l}\text { Patient } \\
\text { No and } \\
\text { gender }\end{array}$} & \multirow{3}{*}{$\begin{array}{c}\text { Age } \\
(y r)\end{array}$} & \multirow{3}{*}{$\begin{array}{l}\text { Dur } \\
(y r)\end{array}$} & \multicolumn{6}{|c|}{ Atlantoaxial distance $(\mathrm{mm})$} & \multicolumn{2}{|l|}{ Effect } \\
\hline & & & \multicolumn{4}{|c|}{ No collar } & \multicolumn{2}{|c|}{ Collar } & \multirow[t]{2}{*}{$(\mathrm{mm})$} & \multirow[t]{2}{*}{$(\%)$} \\
\hline & & & $F$ & $E$ & $I$ & $N$ & $F C$ & IC & & \\
\hline $1 F$ & 72 & 5 & 10 & 0 & 10 & NA & 0 & 0 & 10 & 100 \\
\hline $2 \mathrm{~F}$ & 55 & 21 & 7 & 0 & 7 & 0 & 0 & 0 & 7 & 100 \\
\hline $3 \mathrm{~F}$ & 71 & 24 & 6 & 0 & 6 & 0 & 0 & 0 & 6 & 100 \\
\hline $4 \mathrm{~F}$ & 28 & 12 & 8 & 1 & 7 & 2 & 2 & 1 & 6 & 96 \\
\hline $5 \mathrm{~F}$ & 46 & 5 & 5 & 0 & 5 & 0 & 1 & 1 & 4 & 80 \\
\hline $6 \mathrm{~F}$ & 52 & 10 & 6 & 1 & 5 & 6 & 2 & 1 & 4 & 80 \\
\hline $7 \mathrm{M}$ & 71 & 17 & 7 & 0 & 7 & 0 & 2 & 2 & 5 & 71 \\
\hline $8 \mathrm{~F}$ & 72 & 26 & 6 & 1 & 5 & 2 & 3 & 2 & 3 & 60 \\
\hline $9 \mathrm{~F}$ & 53 & 31 & 10 & 1 & 9 & NA & 5 & 4 & 5 & 56 \\
\hline $10 \mathrm{~F}$ & 32 & 10 & 5 & 0 & 5 & 2 & 3 & 3 & 2 & 40 \\
\hline $11 \mathrm{M}$ & 36 & 11 & 8 & 2 & 6 & 5 & 6 & 4 & 2 & 33 \\
\hline $12 \mathrm{M}$ & 49 & 15 & 10 & 0 & 10 & 7 & 7 & 7 & 3 & 30 \\
\hline $13 \mathrm{~F}$ & 59 & 29 & 9 & 2 & 7 & 7 & 7 & 5 & 2 & 28 \\
\hline $14 M$ & 65 & 38 & 10 & 2 & 8 & 9 & 8 & 6 & 2 & 25 \\
\hline $15 \mathrm{M}$ & 29 & 17 & 7 & 1 & 6 & 6 & 6 & 5 & 1 & 17 \\
\hline $16 \mathrm{~F}$ & 62 & 21 & 9 & 2 & 7 & 7 & 8 & 6 & 1 & 14 \\
\hline $17 \mathrm{~F}$ & 58 & 14 & 8 & 1 & 7 & 7 & 7 & 6 & 1 & 14 \\
\hline $18 \mathrm{~F}$ & 56 & 19 & 8 & 0 & 8 & 7 & 7 & 7 & 1 & 13 \\
\hline $19 \mathrm{~F}$ & 24 & 6 & 9 & 0 & 9 & 7 & 8 & 8 & 1 & 11 \\
\hline $20 \mathrm{~F}$ & 42 & 6 & 8 & 3 & 5 & 8 & 8 & 5 & 0 & 0 \\
\hline $21 \mathrm{~F}$ & 52 & 11 & 8 & 1 & 7 & 8 & 8 & 7 & 0 & 0 \\
\hline $22 \mathrm{~F}$ & 58 & 31 & 9 & 1 & 8 & 1 & 9 & 8 & 0 & 0 \\
\hline
\end{tabular}

Dur $=$ Duration of the disease. $\mathrm{AA}$ distances without collar: $\mathrm{F}=$ in flexion; $\mathrm{E}=$ in extension; $\mathrm{N}=$ neutral position; $\mathrm{I}=$ instability $(\mathrm{F}-\mathrm{E})$. AA distances with collar: $\mathrm{FC}=$ in flexion; IC $=$ instability $(\mathrm{FC}-\mathrm{E})$. Effect $=\mathrm{I}-\mathrm{IC}$; Effect $\%=$ effect as a percentage of $\mathrm{I}$. NA= Not available. Bold values of $\mathrm{N}$ are those which are abnormal.

patients mentioned above did not have neutral position radiographs taken.

In 11 subjects the collar restricted the maximal instability of the AAS by more than $30 \%$; the mean AA distance in the neutral position in these patients was $1.9(\mathrm{SD} 2.3) \mathrm{mm}$ (patients $1-11$ in the table). In the remaining 11 the decrease in AA instability with the collar in place was $30 \%$ or less; mean AA distance in the neutral position in these patients was $6 \cdot 7$

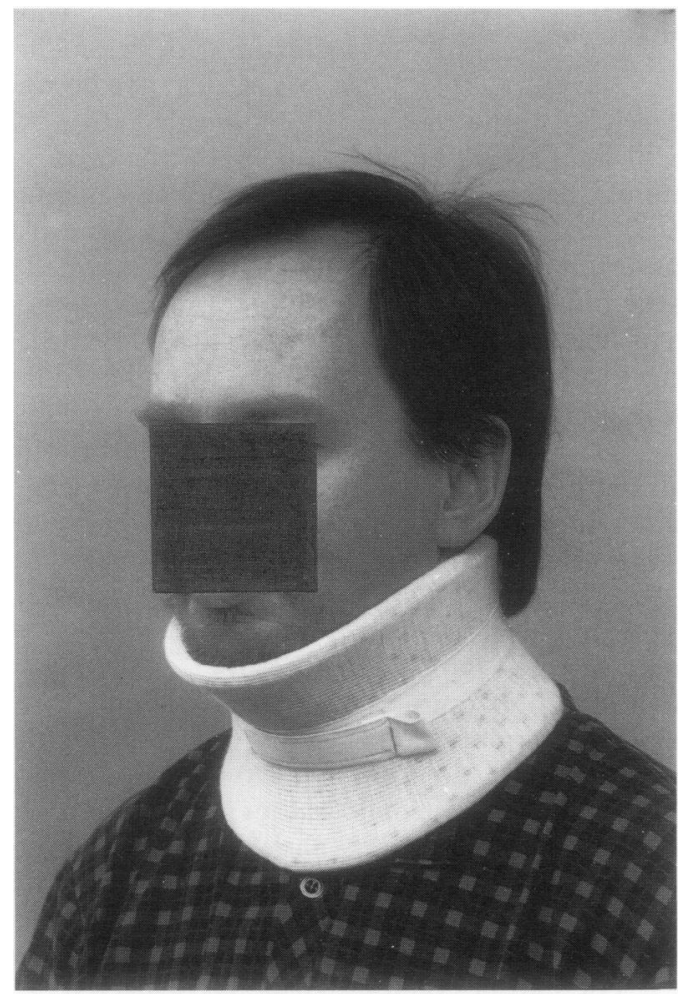

$A$ custom made collar used in the study, made of cell polyethylene foam sheeting $1.25 \mathrm{~cm}$ thick, and rather firm but still slightly flexible. It was made to prevent flexion; the anterior part is strengthened by plastic chips.
(SD 2.1) $\mathrm{mm}$ (patients $12-22$ in the table), and in all but one of these nearly maximal AAS was present also in the neutral radiographs. The difference between AA distances in the neutral position for these two patient groups was statistically significant $(\mathrm{p}<0.001$, unpaired $t$ test).

\section{Discussion}

Johnson et al tested the stabilising effect of five types of collars and orthoses on normal subjects. ${ }^{9}$ None of the tested devices prevented movement of the upper cervical spine, but as much as $45 \%$ of the normal flexion-extension movement at the AA level was restricted by the best braces. The SOMI (sternal-occipitalmandibular immobiliser) brace permitted only $2 \cdot 7(1 \cdot 8)$ degrees of flexion at that level, and it was suggested to be of use in AAS patients. ${ }^{9}$

Althoff and Goldie tested four types of cervical collars and orthoses in $11 \mathrm{RA}$ patients who had severe AAS. ${ }^{7}$ None of the tested devices provided any significant reduction in the maximal AAS during flexion. However, the selection of patients in that study was not optimal, as three of the 11 had almost ankylosed AAS, and in those patients the orthoses obviously could not restrict the maximal AAS. In six of the 11 cases the AAS returned to normal during extension without a collar.

We found that the rather firm custom made collar restricted the instability of AAS significantly in about $50 \%$ of our patients; most of these patients had no AAS with the cervical spine in a neutral position. Diligent use of the collar might reduce the maximal AAS and probably thus also prevent its progression in these patients.

In about $50 \%$ of our patients the collar did not restrict the AA distance in flexion. In all but one of this group there was nearly maximal AAS with the head in the neutral position. Our custom made collar was designed and constructed for the neck with the cervical spine in a good, neutral bearing. Naturally, therefore, if maximal AAS exists under those conditions, it cannot be reduced by the collar.

Only two of our subjects did not fit with our hypothesis of two patient groups, classified according to their neutral position radiographs, obtaining and failing to obtain a favourable effect from a collar. The collar seemed to be able to provide support for a neutral position of the upper cervical spine. In patient No 6, the collar did limit the instability even though AAS was present in the neutral position. For this patient, the collar was made with the neck placed in a more extended neutral position than that in which the neutral radiograph was taken. This suggests that, if a patient who has AAS in the neutral position is able to extend the neck, the position of the atlas may be normalised and the collar thus be more effective. In patient No 22 , in contrast, the collar did not restrict the instability, although no AAS was present in the neutral position. It must be assumed either that we failed to produce a suitable collar for her, or that the 
collar was not positioned correctly during the radiograph.

In nearly half of the subjects studied by Althoff and Goldie, the AA distance during extension was larger with a firm collar than without one, and they concluded that the harder collars would force the atlas to subluxate anteriorly in some subjects. ${ }^{7}$ It is possible also that some of their patients had AAS in the neutral position and thus the harder collars would have prevented repositioning during extension. This is not an adverse effect of a collar, but rather that the firm collar supports the neutral position as it is intended to do. Cervical extension is a fairly rare position in everyday life and so this effect probably does not have great clinical significance. To avoid unnecessary exposure to radiation, we did not take radiographs during neck extension with the collar in place.

Compliance with wearing a collar is often a problem. A radiograph taken during neck flexion with the collar in place, by providing evidence of its effectiveness in reducing the maximal AAS, could motivate both patient and doctor to take a favourable view of the use of a collar. For the present, there is no evidence of collars preventing radiological progression in the rheumatoid cervical spine. ${ }^{10-12}$ This may be partly attributable to the choice of patients and the frequently indolent attitude to the use of a collar. ${ }^{12}$ A positive effect of the collars would probably be found in those patients who do not have AAS with the neck held in a neutral position and who are well motivated to use a collar.

The collars are known to offer some relief from pain, partly because they warm the tensile muscles. ${ }^{2357}$ They can also be of psychological value by giving a feeling of stability. ${ }^{5}$ Our results showed that a stiff collar restricted AA instability and offered real stability in selected cases. We suggest that when an unstable AAS is diagnosed, an additional lateral view radiograph should be taken with the cervical spine in a neutral position, in order to determine the prevalent AA position; a collar would best restrict AA instability in patients who do not have AAS in that neutral position.

The study was financially supported by the Rheumatism Research Foundation, Helsinki, Finland. We are grateful to Ms Leena Niskanen and Ms Soili Paalanen for producing the collars. We thank professor Heikki Isomäki for critical reviews collars. We thank
of the manuscript.

1 Agarwal A K, Peppelman W C Jr, Kraus D R, Eisenbeis C $\mathrm{H} \mathrm{Jr}$. The cervical spine in rheumatoid arthritis. $B M \mathcal{F}$ 1993; 306: 79-80.

2 Konttinen Y T, Santavirta S, Kauppi M, Moskowich R. The rheumatoid cervical spine. Curr Opin Rheumatol 1992; 3: rheumatoid

3 Bland J H. Rheumatoid arthritis of the cervical spine. $f$ Rheumatol 1974; 1: 319-42.

4 Bland J H. Rheumatoid subluxation of the cervical spine. F Rheumatol 1990; 17: 134-7.

5 Halla J T, Hardin J G, Vitec J, Alarcón G S. Involvemen of the cervical spine in rheumatoid arthritis. Arthritis Rheum 1989; 32: 652-9.

6 Eulderink F, Meijers K A. Pathology of the cervical spine in rheumatoid arthritis: a controlled study of $\mathbf{4 4}$ spines. f Pathol 1976; 120: 91-108.

7 Althoff B, Goldie IF. Cervical collars in rheumatoid atlantoaxial subluxation: a radiographic comparison. Ann Rheum Dis 1980; 39: 485-9.

8 Kauppi M, Hakala $M$. Prevalence of cervical spine subluxations and dislocations in a community-based rheumatoid arthritis population. Scand $\mathfrak{f}$ Rheumatol 1994; 23: 133-6.

9 Johnson R M, Hart D L, Simmons E F, Ramsby G R, Southwick W O. Cervical orthoses. F Bone foint Surg Am 1977; 59: 332-9.

10 Mathews J A. Atlanto-axial subluxation in rheumatoid arthritis - a 5-year follow-up study. Ann Rheum Dis 1974 33: 526-31.

11 Pellicci P M, Ranawat C S, Tsairis P, Bryan W J. A prospective study of the progression of rheumatoid arthritis of the cervical spine. 7 Bone foint Surg Am 1981; 63: 342-51.

12 Smith P H, Benn R T, Sharp J. Natural history of theumatoid cervical luxations. Ann Rheum Dis 1972; 31 . rheum 